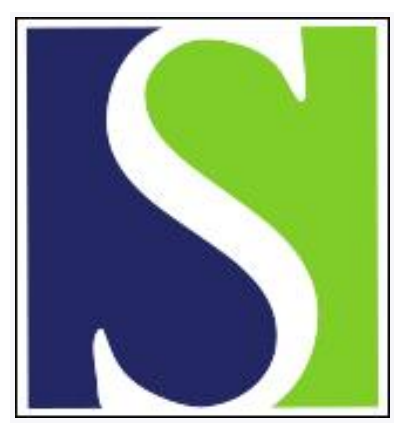

Scand J Work Environ Health 1985;11(1):33-37

https://doi.org/10.5271/sjweh.2256

Issue date: Feb 1985

Relation of mercury exposure to elemental mercury levels in the urine and blood.

by Yoshida $M$

This article in PubMed: www.ncbi.nlm.nih.gov/pubmed/3992219

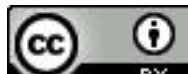




\title{
Relation of mercury exposure to elemental mercury levels in the urine and blood
}

\author{
by Minoru Yoshida, MS $^{1}$
}

\begin{abstract}
YOSHIDA M. Relation of mercury exposure to elemental mercury levels in the urine and blood. Scand $J$ Work Environ Health 11 (1985) 33-37. The levels of elemental and inorganic mercury were measured in urine and blood samples from workers in thermometer manufacturing factories. The inorganic mercury levels in the urine did not correlate with the levels of mercury exposure for each worker. However, a significant correlation was noted between elemental mercury levels in the urine and the levels of individual exposure. A significant correlation was also found between elemental mercury levels in the urine and mercury levels in the blood. These findings suggest that the determination of elemental mercury in urine may serve as a useful indicator for assessing levels of recent exposure to mercury vapor, as well as the level of inorganic mercury in the blood.
\end{abstract}

Key terms: air, exposure, individual, inorganic.

Individual exposure to mercury has usually been evaluated from air measurements, but analyses of mercury in the urine and blood have also been made. In particular, when the fluctuations in air concentration are small, the urinary concentration of mercury has proved useful as an indicator for evaluating mercury exposure, a positive correlation has been shown between the time-weighted average (TWA) of the exposure and the urinary mercury levels (13). However, when the day-to-day variations in air concentration are great, the correlation between exposure and urinary mercury levels tend to be very poor or negative (1).

In 1974 Henderson et al (5) found that a new technique which measured the chemical species of mercury, could be used to detect elemental mercury $\left(\mathrm{Hg}^{\circ}\right)$ in workers' urine in an alkali-chlorine industrial factory. My co-workers and I have also reported $(15,17)$ that elemental mercury rapidly appears in urine after exposure to relatively high mercury levels. Thus, when air concentrations fluctuate, the urinary levels of elemental mercury might reflect the exposure levels for each individual on a given day.

Recently Satoh (12) established an analytical method to measure elemental mercury in blood and urine samples and found, in animal experiments, that elemental mercury could be detected in the bloodstream following exposure to a heavy mercury vapor (6). However, it remains unclear whether the elemental mercury concentrations in the blood and urine relate significantly to the degree of exposure.

\footnotetext{
1 Department of Public Health, St Marianna University School of Medicine, Kawasaki Japan.
}

Reprint requests to: Mr M Yoshida, Department of Public Health, St Marianna University School of Medicine, 2095, Sugao, Miyamaeku, Kawasaki 213, Japan.
The purpose of the present study was to investigate elemental mercury concentrations of blood and urine in relation to the extent of worker exposure and to assess whether determinations of elemental mercury in urine and blood are useful for evaluating recent exposure levels of workers.

\section{Materials and methods}

A total of 27 male workers, aged 23-61 years and employed for $1-33$ years in four factories manufacturing mercury thermometers (the TO, SA, TE, and $\mathrm{T}$ factories), were investigated.

\section{Mercury in the work environment}

Mercury vapor in the work environment air was collected in an air bubbler containing a scrubbing solution of acid permanganate. The sampler (intake $1 \mathrm{l} /$ $\mathrm{min}$ ) was placed at a fixed location in the work area. A sampling of $100 \mathrm{l}$ of air was performed once in the morning and afternoon. The mercury collected in the sampler was measured by flameless atomic absorption spectrophotometry.

\section{Individual mercury exposure}

Individual exposure to mercury was estimated by a personal sampling technique, in which mercury vapor was collected as air passed through glass tubes filled with gold wire or by a spin-environmentrics mercury dosimeter badge (Sipin Co, New York). The sampling devices were directly attached to the worker's collar in his breathing zone and worn throughout the work period. After collection, the mercury was removed from the gold amalgam by thermal decomposition, absorbed in an acid-permanganate scrubber, and subsequently measured by flameless atomic absorption spectrophotometry. 


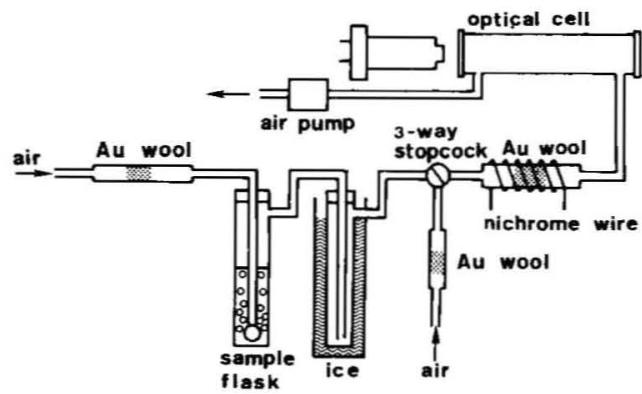

Figure 1. Apparatus for the determination of elemental mercury in urine and blood. ( $\mathrm{Au}=$ gold)

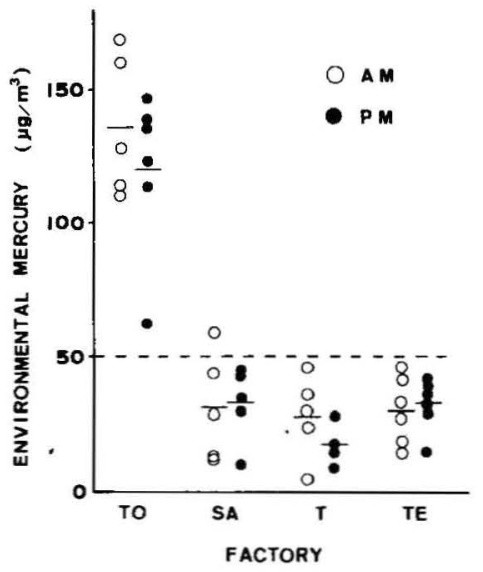

Figure 2. Airborne mercury levels in the morning (AM) and afternoon (PM) at four thermometer factories. The measurements were made with area sampling as described in the Methods section. (Solid horizontal bars $=$ mean values of airborne mercury levels; dotted lines = hygenic standard)

\section{Elemental mercury in urine and blood}

After the end of each workday, urine samples were immediately collected in mercury-free bottles and frozen in a dry ice-acetone solution within $3 \mathrm{~min}$ of collection to prevent microorganism contamination. About $10 \mathrm{ml}$ of blood was obtained by venipuncture at the same time as the urine samples, and $5 \mathrm{ml}$ of this sample was poured into another polyethylene tube containing $5 \mathrm{ml}$ of chilled $1 \%$ ethanol-saline solution, which inhibits the further oxidation of elemental mercury by catalase, and frozen in the same manner as the urine samples. The other $5 \mathrm{ml}$ was employed for the measurement of inorganic mercury. The samples were then transported to our laboratory. The analysis of elemental mercury was performed on the day after collection. The elemental mercury concentration in urine and blood was determined, according to the method of Satoh et al (11), with the system shown in figure 1 . The sample volume used was $5 \mathrm{ml}$ for blood and 30 to $50 \mathrm{ml}$ for urine. To the sample transferred to the sample flask, one or two drops of n-octyl alcohol solution was added to prevent foaming, and an airstream was passed through the solution. The expelled elemental mercury
Table 1. Mercury concentrations of the blood and urine of workers in thermometer factories. (ND = not detected)

\begin{tabular}{|c|c|c|c|c|c|}
\hline \multirow[b]{2}{*}{$\begin{array}{l}\text { Num- } \\
\text { ber }\end{array}$} & \multirow[b]{2}{*}{$\begin{array}{c}\text { Personal } \\
\text { exposure } \\
\left(\mu \mathrm{g} / \mathrm{m}^{3}\right)\end{array}$} & \multicolumn{2}{|c|}{ Blood } & \multicolumn{2}{|c|}{ Urine } \\
\hline & & $\begin{array}{c}\text { Inorganic } \\
\text { mercury } \\
(\mathrm{nmol} / \mathrm{l})\end{array}$ & $\begin{array}{l}\text { Elemental } \\
\text { mercury } \\
\text { (nmol/f) }\end{array}$ & $\begin{array}{c}\text { Inorganic } \\
\text { mercury } \\
\text { (nmol/l) }\end{array}$ & $\begin{array}{c}\text { Elemental } \\
\text { mercury } \\
\text { (nmol/l) }\end{array}$ \\
\hline \multicolumn{6}{|c|}{ TO factory } \\
\hline $\begin{array}{l}1 \\
2 \\
3 \\
4 \\
5 \\
6 \\
7 \\
8 \\
9\end{array}$ & $\begin{array}{c}149 \\
226 \\
138 \\
223 \\
150 \\
102 \\
209 \\
. . \\
.\end{array}$ & $\begin{array}{r}1150 \\
1090 \\
1080 \\
850 \\
695 \\
565 \\
\cdots \\
530 \\
550\end{array}$ & $\begin{array}{c}0.50 \\
0.46 \\
0.40 \\
0.40 \\
0.27 \\
0.30 \\
. .30 \\
0.30 \\
1.10\end{array}$ & $\begin{array}{r}1010 \\
705 \\
1120 \\
1470 \\
1090 \\
383 \\
810 \\
860 \\
510\end{array}$ & $\begin{array}{l}0.47 \\
0.74 \\
0.50 \\
0.57 \\
0.75 \\
0.73 \\
1.22 \\
0.50 \\
0.94\end{array}$ \\
\hline \multicolumn{6}{|c|}{$T$ factory } \\
\hline $\begin{array}{l}10 \\
11 \\
12 \\
13 \\
14\end{array}$ & $\begin{array}{l}65 \\
50 \\
60 \\
30 \\
25\end{array}$ & $\begin{array}{r}240 \\
275 \\
\cdots \\
80 \\
105\end{array}$ & $\begin{array}{l}\text { ND } \\
\text { ND } \\
\text { ND } \\
\text { ND }\end{array}$ & $\begin{array}{r}500 \\
615 \\
1500 \\
96 \\
384\end{array}$ & $\begin{array}{l}0.14 \\
0.14 \\
0.38 \\
0.08 \\
0.08\end{array}$ \\
\hline \multicolumn{6}{|c|}{$S A$ factory } \\
\hline $\begin{array}{l}15 \\
16\end{array}$ & $\begin{array}{l}79 \\
66\end{array}$ & $\begin{array}{r}250 \\
80\end{array}$ & $\begin{array}{l}\text { ND } \\
\text { ND }\end{array}$ & $\begin{array}{l}690 \\
240\end{array}$ & $\begin{array}{l}0.12 \\
0.05\end{array}$ \\
\hline \multicolumn{6}{|c|}{$T E$ factory } \\
\hline $\begin{array}{l}17 \\
18 \\
19 \\
20 \\
21 \\
22 \\
23 \\
24 \\
25 \\
26 \\
27\end{array}$ & $\begin{array}{r}140 \\
78 \\
75 \\
75 \\
70 \\
75 \\
61 \\
45 \\
64 \\
50 \\
58\end{array}$ & $\begin{array}{l}343 \\
326 \\
274 \\
274 \\
257 \\
120 \\
120 \\
202 \\
147 \\
111 \\
129\end{array}$ & $\begin{array}{l}0.31 \\
0.30 \\
\text { ND } \\
\text { ND } \\
\text { ND } \\
\text { ND } \\
\text { ND } \\
\text { ND } \\
\text { ND } \\
\text { ND } \\
\text { ND }\end{array}$ & $\begin{array}{r}640 \\
650 \\
367 \\
785 \\
1560 \\
1000 \\
875 \\
550 \\
1020 \\
580 \\
705\end{array}$ & $\begin{array}{l}0.37 \\
0.30 \\
0.22 \\
0.27 \\
0.27 \\
0.19 \\
0.03 \\
0.14 \\
0.22 \\
0.12 \\
0.17\end{array}$ \\
\hline
\end{tabular}

was collected with a gold wire absorber attached to the outlet of the sample flask. The elemental mercury absorbed on the gold wire was extracted from the gold amalgam by thermal decomposition and determined directly by flameless atomic absorption spectrophotometry. The absolute sensitivity of the elemental mercury measurement by this method was $1.0 \mathrm{nmol}$, with an error margin of less than $10 \%$.

\section{Inorganic mercury in urine and blood}

The inorganic mercury concentration of urine and blood was determined by the method of Magos (7), which has a sensitivity of $2.5 \mathrm{nmol}$.

\section{Results}

Figure 2 shows the airborne mercury levels in the morning and afternoon at the four factories manufacturing thermometers. The airborne mercury levels at the TO factory were the highest among the four factories and those of both the morning and afternoon exceeded the hygienic standard of $50 \mu \mathrm{g} / \mathrm{m}^{3}$. This factory was a small building and employed a process of pouring metallic mercury into thermometer blanks and flame-closing the thermometer glass tips. When we investigated this factory, the window of the 
work area was closed, and, moreover, ventilation was very poor. However, no clinical signs of chronic mercury vapor poisoning, such as gingivitis, tremor of the hands or erethism, were found.

Table 1 shows the elemental and inorganic mercury concentrations of the urine and blood and the levels of mercury exposure for each individual. In the TO factory, the inorganic mercury concentrations of the blood and the levels of individual mercury exposure of six workers were higher than those of the other workers. Furthermore elemental mercury levels ranging from 0.08 to $1.22 \mathrm{nmol} / \mathrm{l}$ could be detected in the blood of the workers. At the $\mathrm{T}$ factory, in which the airborne mercury levels were relatively low and under the hygienic standard of $50 \mu \mathrm{g} / \mathrm{m}^{3}$, elemental mercury could not be detected in the blood of the workers. At the TE factory, elemental mercury was detected in the blood of two workers (numbers $17 \& 18$ in table 1), who had an average mercury exposure in excess of the hygienic standard, but mercury could not be detected in the blood of workers with low exposure. The elemental mercury concentration of the workers' blood constituted less than $0.2 \%$ of the inorganic mercury in the blood. On the other hand, elemental mercury was detected in urine samples from all the workers, and the values were in the range of 0.27 to $1.10 \mathrm{nmol} / \mathrm{l}$, which constituted less than $1 \%$ of the inorganic mercury in the urine. The relationship between the elemental mercury concentration in the blood and urine was less definite because of insufficient data (figure 3 ).

Figure 4 illustrates the relationship between the levels of individual mercury exposure and concentrations of inorganic mercury in the urine of 25 workers. The urinary mercury values were not corrected for specific gravity. The correlation between the inorganic mercury concentrations of the urine and concurrently measured levels of individual exposure was poor, with a correlation coefficient of 0.348 ( $p<0.10$ ). However, the elemental mercury concentrations in the urine correlated well with the levels of individual mercury exposure on the day of collection (figure 5).

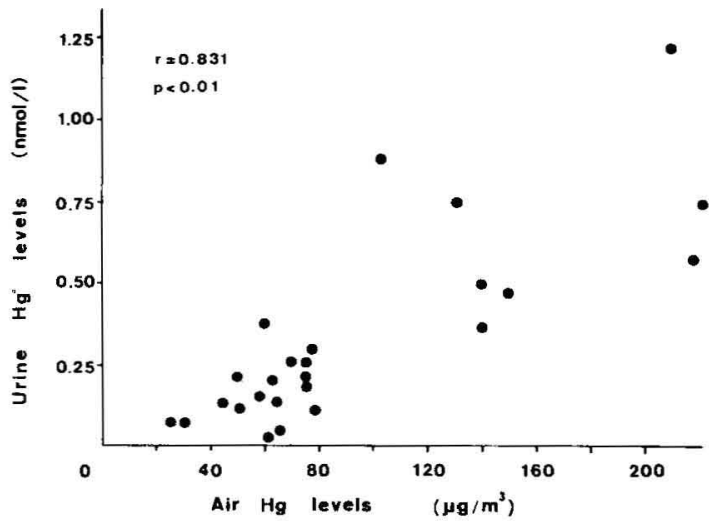

Figure 5. Relationship between personal exposure levels (time-weighted average) and the concentrations of elemental mercury $\left(\mathrm{Hg}^{\circ}\right)$ in the urine. $(\mathrm{Hg}=$ mercury)
The urinary elemental mercury concentrations appeared to reflect the mercury exposure levels of each worker better than the urinary inorganic mercury concentrations. Furthermore, the urinary elemental mercury concentrations correlated with the blood mercury levels (figure 6) and thus may serve as a better indicator for evaluating recent exposure $(14,16)$.

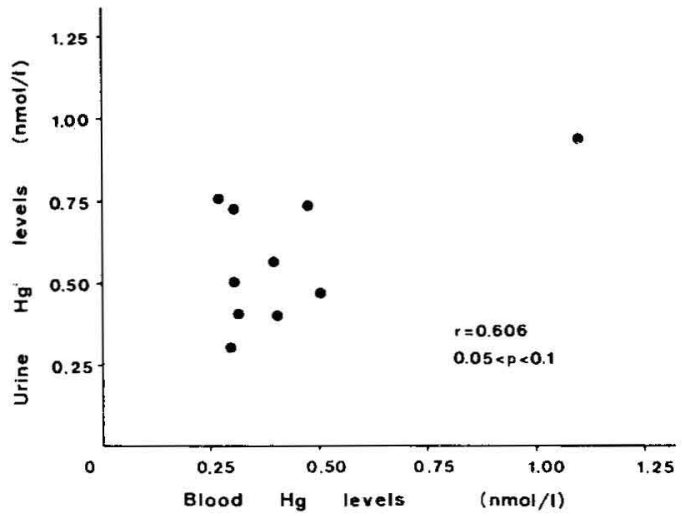

Figure 3. Relationship between the elemental mercury $\left(\mathrm{Hg}^{\circ}\right)$ concentrations of the blood and urine.

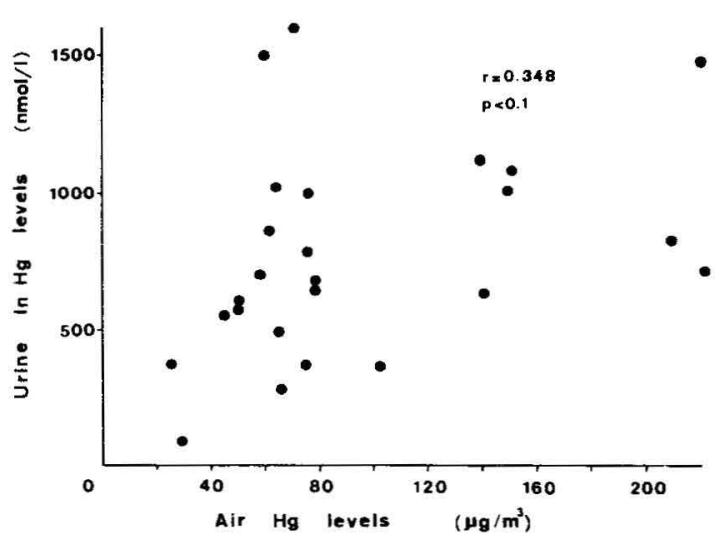

Figure 4. Relationship between personal exposure levels (time-weighted average) and the concentrations of inorganic mercury ( $\mathrm{ln} \mathrm{Hg}$ ) in the urine (uncorrected for specific gravity). ( $\mathrm{Hg}=$ mercury)

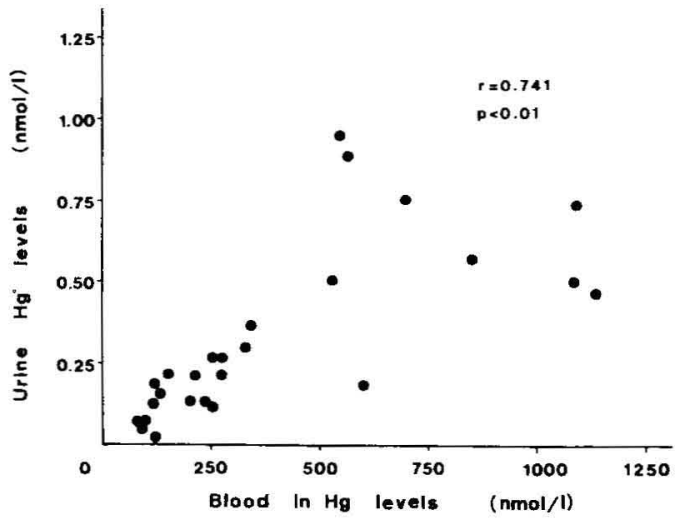

Figure 6. Relationship between concentrations of inorganic mercury $(\mathrm{In} \mathrm{Hg})$ in the blood and elemental mercury $\left(\mathrm{Hg}^{\circ}\right)$ in the urine. 


\section{Discussion}

After inhalation, elemental mercury is easily absorbed into the bloodstream and is rapidly oxidized through the mercurous $\left(\mathrm{Hg}^{+}\right)$to the mercuric $\left(\mathrm{Hg}^{++}\right)$ion. Despite rapid oxidation, some elemental mercury is known to exist in the bloodstream in its original form long enough to reach all tissue and organs. With respect to elemental mercury in the blood, Magos (8) reported that, when samples of diluted blood were exposed to mercury vapor in vitro, $8 \%$ of the retained mercury was in the elemental form after $5 \mathrm{~min}$ and $4 \%$ after $15 \mathrm{~min}$ of exposure, and dissolved elemental mercury existed in the blood. On the other hand, Satoh (12) in his radioactive isotope experiments with animals, proved that elemental mercury could be detected in the bloodstream during shortterm high exposure to mercury vapor. The elemental mercury concentration in the venous blood was lower than that in the arterial blood, and the concentration diminished rapidly with time after the termination of the exposure. On the basis of the data of Satoh (12), the collection of blood samples in the present study was performed from venous blood immediately after the end of the workday. As a result, elemental mercury, ranging from 0.27 to $1.10 \mathrm{nmol} / \mathrm{l}$, was detected in the venous blood of workers exposed to high levels of mercury vapor.

Reduction of the mercuric ion to elemental mercury in mammals has been reported by Clarkson \& Rothstein (3). They described the exhalation of volatile mercury, which was subsequently confirmed to be elemental mercury, by rats injected with mercury chloride. According to the animal experiments of Magos (9) and Dunn et al (4), the amount of elemental mercury produced by the reduction of mercuric ions is very small, and, moreover, it was suggested that most of the reduced mercury would be reoxidized before it could be exhaled. From these considerations, the elemental mercury detected in the blood of workers after mercury vapor exposure is more likely to be unoxidized elemental mercury persisting in blood after exposure, rather than elemental mercury produced by the reduction of the mercuric ion. As the data are, as yet, insufficient, no relationship could be elucidated between the elemental mercury concentrations of the blood and the levels of individual mercury exposure $(r=0.556, p>0.1)$. However, even if inorganic mercury concentrations in the blood are equal among workers, since more elemental mercury could be detected in the blood of those exposed to higher air mercury levels than those exposed to lower air mercury levels, at least it can be stated that concentrations will tend to increase with the level of mercury exposure. The elemental mercury concentration of the blood was less than $0.2 \%$ of the corresponding inorganic mercury concentration. This finding seems to suggest that, after the inhalation of elemental mercury, the amount of elemental mercury passing the blood-brain barrier is less than $0.2 \%$.
On the other hand, elemental mercury has been detected in the urine of workers exposed to mercury vapor $(5,14,15)$. The occurrence of trace amounts of elemental mercury is considered to be due to (i) the reduction of mercuric ion by certain types of microorganisms present in the urine and (ii) direct urinary excretion following glomerular filtration of the elemental mercury persisting in the blood. In this study, the collection of the urine samples was performed immediately after the end of the workday, and, moreover, frozen until analysis. Therefore, it cannot be considered that the mercuric ion in the urine was reduced to elemental mercury by microorganisms. After mercury exposure, elemental mercury persisting in the blood is considered to be excreted directly in the urine via glomerular filtration, as was described by Henderson et al (5) and Ishihara et al (6). In addition the finding of a relationship between the elemental mercury concentration of the blood and urine is supported, even though the results were statistically significantly weak due to insufficient data (as shown in figure 3 ).

In a previous paper (17) my co-workers and I suggested that elemental mercury may appear in the urine quite rapidly after exposure to mercury vapor, and the appearance of elemental mercury in the urine is related to the level of mercury exposure. The urinary concentrations of elemental mercury were found to correlate well with the concurrently measured levels of individual mercury exposure (figure 5), but the relationship between the levels of individual exposure and those of inorganic mercury was poor (figure 4). In the study by Nakaaki et al (10), inorganic mercury taken up in the body was excreted rather slowly; an increase in urinary excretion became evident after $10 \mathrm{~d}$ of exposure at $40-60 \mu \mathrm{g} / \mathrm{m}^{3}$. Cherian et al (2) also found that mercury is pooled in the kidney before entering the urine, and the biological half-time for mercury loss from the kidney is approximately $64 \mathrm{~d}$. As numerous investigators have already noted, urinary concentrations of inorganic mercury would tend to reflect levels of chronic exposure, perhaps kidney accumulation of mercury, rather than those of recent exposure. It appears therefore that the urinary excretion of elemental mercury is faster than that of inorganic mercury and, moreover, can be expected to reflect the levels of individual exposure on that same day.

It is known that, shortly after exposure to mercury vapor, the mercury blood concentration rises rapidly. The rapid appearance of mercury in the blood suggests the possibility that recent exposure can be assessed from measurements of the mercury in the blood. In the present study, the mercury concentrations of the blood did in fact correlate well with the levels of individual exposure on the day of collection (figure 6), with a correlation coefficient of $0.741(\mathrm{p}<$ 0.01 ). In addition there was a significant correlation between blood mercury levels and urinary elemental 
mercury levels for each individual. These findings indicate that it may be possible to estimate recent exposure from the urinary elemental mercury concentrations, as well as the blood mercury concentrations. Determinations of the elemental and inorganic species of mercury in urine samples can provide information on both recent exposure and the body burden resulting from chronic exposure to mercury vapor.

\section{Acknowledgments}

The author would like to acknowledge the continuing guidance of Professor Y Yamamura (St Marianna University School of Medicine) and Dr $\mathrm{H}$ Satoh (Fukushima Medical School).

\section{References}

1. Bell ZG, Wood MW, Kuryla LA. Mercury exposure evaluations and their correlation with urine mercury excretions: 3 . Time-weighted average (TWA) mercury exposures and urine mercury levels. J Occup Med 15 (1973) $501-508$

2. Cherian M, Hursh JB, Clarkson TW, Allen J. Radioactive mercury distribution in biological fluids and excretion in human subjects after inhalation of mercury vapor, Arch Environ Health 33 (1978) 109-114.

3. Clarkson $T$, Rothstein $A$. The excretion of volatile mercury by rats injected with mercuric salt. Health Phys 10 (1964) 1115-1121.

4. Dunn JD, Clarkson TW, Magos L. Ethanol-increased exhalation of mercury in mice. Br J Ind Med 35 (1978) $241-244$.

5. Henderson R, Shotwell HP, Krause L. Analyses for total, ionic, and elemental mercury in urine as basis for a biologic standard. Am Ind Hyg Assoc J 35 (1974) $576-580$.

6. Ishihara N, Nakaaki K, Satoh H, Yamamoto R, Miya- saka Y, Urushiyama K, Suzuki T. Urinary excretion in the early phase of mercury vapor exposure in rabbits. J Appl Toxicol 2 (1982) 151-155.

7. Magos L. Selective atomic-absorption determination of inorganic mercury and methylmercury in undigested biological samples. Analyst 96 (1971) 847-857.

8. Magos L. Mercury-blood interaction and mercury uptake by the brain after vapor exposure. Environ Res 1 (1968) 323-337.

9. Magos L. Uptake of mercury by the brain. $\mathrm{Br} \mathrm{J}$ Ind Med 25 (1968) 315-318.

10. Nakaaki K, Fukabori S, Tada O. An experimental study on inorganic mercury vapor exposure. J Sci Labour 51 (1975) 705-716.

11. Satoh H, Hursh JB, Clarkson TW. Selective determination of elemental mercury in blood and urine exposed to mercury vapor in vitro. J Appl Toxicol 1 (1981) $177-181$.

12. Satoh $\mathbf{H}$. Effects of ethanol on the metabolism of dogs inhaling mercury [in Japanese]. In: Proceedings of 55th Annual Meeting of Japan Association of Industrial Health, Nagoya (1982). pp 620-621.

13. Smith RG, Vorwald AJ, Patil LS, Mooney TT. Effect of exposure to mercury in the manufacture of chlorine. Am Ind Hyg Assoc J 31 (1970) 687—700.

14. Stopford W, Bundy SD, Goldwater LJ, Bittikofer JK. Microenvironmental exposure to mercury vapor. Am Ind Hyg Assoc J 31 (1978) 687-700.

15. Yoshida M, Yamamura Y. Elemental mercury in the urine of workers exposed to mercury vapor - A survey in thermometer factories. Jpn J Ind Health 23 (1981) $422-423$.

16. Yoshida M, Yamauchi $H$, Arai F, Yamamura $Y$. A study on mercury exposure monitoring - Comparison of environmental monitoring and personal monitoring [in Japanese]. Jpn J Hyg 35 (1980) 543-549.

17. Yoshida M, Yamamura Y. Elemental mercury in urine from workers exposed to mercury vapor. Int Arch Occup Environ Health 51 (1982) 99-104.

Received for publication: 1 July 1984 